\title{
BMJ Open Using the extended self-regulatory model to characterise diabetes medication adherence: a cross- sectional study
}

Olayinka O Shiyanbola, ${ }^{1}$ Elizabeth Unni, ${ }^{2}$ Yen-Ming Huang, ${ }^{1}$ Cameron Lanier ${ }^{1}$

To cite: Shiyanbola 00, Unni E, Huang Y-M, et al. Using the extended self-regulatory model to characterise diabetes medication adherence: a crosssectional study. BMJ Open 2018:8:e022803. doi:10.1136/ bmjopen-2018-022803

- Prepublication history for this paper is available online. To view these files, please visit the journal online (http://dx.doi org/10.1136/bmjopen-2018022803).

Received 27 March 2018 Revised 9 August 2018 Accepted 27 September 2018

Check for updates

(c) Author(s) (or their employer(s)) 2018. Re-use permitted under CC BY-NC. No commercial re-use. See rights and permissions. Published by BMJ.

${ }^{1}$ Division of Social and Administrative Sciences, School of Pharmacy, University of Wisconsin-Madison, Madison, Wisconsin, USA

${ }^{2}$ Department of Pharmaceutical Sciences, College of Pharmacy, Roseman University of Health Sciences, Utah, USA

Correspondence to Dr Olayinka 0 Shiyanbola; Olayinka.Shiyanbola@wisc.edu

\section{ABSTRACT}

Objectives To cluster the adherence behaviours of patients with type 2 diabetes based on their beliefs in medicines and illness perceptions and examine the psychosocial, clinical and sociodemographic characteristics of patient clusters.

Design Cross-sectional study.

Setting A face-to-face survey was administered to patients at two family medicine clinics in the Midwest, USA.

Participants One hundred and seventy-four $\geq 20$-year-old, English-speaking adult patients with type 2 diabetes who were prescribed at least one oral diabetes medicine daily were recruited using convenience sampling.

Primary and secondary outcome measures Beliefs in medicines and illness perceptions were assessed using the Beliefs about Medicines Questionnaire and the Brief IIIness Perception Questionnaire, respectively. Self-reported medication adherence was assessed using the Morisky Medication Adherence Scale. Psychosocial correlates of adherence, health literacy and selfefficacy were measured using the Newest Vital Sign and the Self-efficacy for Appropriate Medication Use, respectively. Two-step cluster analysis was used to classify patients.

Results Participants' mean age was 58.74 (SD=12.84). The majority were women (57.5\%). Four clusters were formed (non-adherent clusters: ambivalent and sceptical; adherent clusters: indifferent and accepting). The ambivalent cluster $(n=30,17.2 \%)$ included lowadherent patients with high necessity beliefs, high concern beliefs and high illness perceptions. The sceptical cluster $(n=53,30.5 \%)$ included low adherent patients with low necessity beliefs but high concern beliefs and high illness perceptions. Both the accepting ( $n=40$, $23.0 \%)$ and indifferent $(n=51,29.3 \%)$ clusters were composed of patients with high adherence. Significant differences between the ambivalent, sceptical, accepting and indifferent adherent clusters were based on selfefficacy, illness perception domains (treatment control and coherence) and haemoglobin A1c $(p<0.01)$.

Conclusions Patients with diabetes in specific nonadherent and adherent clusters still have distinct beliefs as well as psychosocial characteristics that may help providers target tailored medication adherence interventions.
Strengths and limitations of this study

- This is the first study to use a clustering technique to allow for algorithm-based grouping based on both beliefs in medicines and illness perceptions founded on the Extended Self-Regulatory Model among patients with diabetes.

- This study highlighted the importance of content and theory-driven components to enable a possible mechanism for the development of tailored adherence interventions.

- This study focused on the impact of patient psychosocial factors such as their individual perceptions of medication and illness, self-efficacy and health literacy in the management of diabetes.

- A convenience sample from two clinics in one state, hereby limiting the generalisability of the study.

- The use of a self-reported measure to evaluate medication adherence, rather than objective measures.

\section{INTRODUCTION}

Medication adherence, defined as the extent to which taking medications corresponds with recommendations by a healthcare provider is essential for treatment success. ${ }^{1}$ Poor adherence results in increased risk of mortality, increased emergency room visits and reduced quality of life..$^{2-5}$ In general, rates of medication adherence are below 50\%. ${ }^{6}$ However, for patients with type 2 diabetes, these rates are as low as $36 \% .^{7}$ It is estimated that a $10 \%$ improvement in diabetes medication adherence would lead to at least a $6.6 \%$ reduction in hospitalisations. ${ }^{7}$

Among patients with diabetes, medication adherence has been found to be influenced by psychosocial factors, such as beliefs about illness and treatment, self-efficacy and perceived control, self-regulation and emotional states. ${ }^{8}$ Of the various factors that influence medication adherence, Horne and Weinman showed that sociodemographic and clinical factors explain only a small amount of variance in medication adherence, whereas 
illness perceptions and patient beliefs in medicines are substantial independent predictors. ${ }^{9}$ Since patient clinical and sociodemographics are difficult to change, it makes sense to focus on patient factors that are modifiable, practical for interventions and can be addressed by health providers.

Studies based on the Extended Self-Regulatory Model show that when patients are diagnosed with an illness, they develop a pattern of beliefs about their condition and treatment, which then influences their medication adherence. ${ }^{10-15}$ The Self-Regulatory Model (also called the Common Sense Model) was developed to explain illness-related coping behaviours including adherence to treatment, based on patient perceptions of their illness. ${ }^{16}$ Horne et al extended the Self-Regulatory Model by integrating beliefs about treatment when research identified beliefs about treatment as proximal determinants of coping strategies such as medication adherence compared with illness perceptions. ${ }^{910}$ In prior research, Phillips and colleagues suggested that patient adherence was greater when illness and treatment perceptions were addressed or discussed during patients' medical encounter and that healthcare providers were better able to judge patient agreement regarding the illness and treatment when patients reported these discussions occurred. ${ }^{1718}$

To design feasible and useful medication adherence interventions, Horne et al originally classified patients with chronic illnesses into four attitudinal groups (accepting, ambivalent, sceptical and indifferent) based on their beliefs about their treatment. ${ }^{19}$ While 'accepting' patients, with high necessity beliefs and low concerns, had the highest medication adherence, 'sceptical' patients, with low perceived need of medications and high concerns, had the lowest adherence levels. The other patient groups, including the 'ambivalent' (high necessity beliefs and high concerns), and the 'indifferent' (low necessity beliefs and low concerns) were also likely to be non-adherent. ${ }^{19}$ Although medication non-adherence is a common problem among patients with chronic illnesses, they hardly discuss this behaviour with their health providers during routine visits. ${ }^{20}$ Various available tools used to identify medication adherence are not usable in clinical consultations because of the short time available to providers. ${ }^{21}$ Hence, clustering patients' adherence behaviour based on their beliefs may provide a mechanism for providers to focus on the specific belief needs of the patients in the context of their psychosocial characteristics. A previous study based on the Extended Self-Regulatory Model used both illness perceptions and beliefs in medicines to cluster patients with asthma and was able to develop the same clusters as developed by Horne et al. ${ }^{192}$ Additionally, each cluster had psychosocial characteristics that were unique to them. However, further studies were needed to determine whether the four attitudinal group structure that includes illness perceptions also holds with other chronic disease conditions.

Clustering will provide a mechanism for providers to have a more tailored approach to addressing adherence than the general 'one size fits all' approach. For example, the counselling needed for a sceptical patient can be very different from an ambivalent patient. Although both these sets of patients have issues with their beliefs in medicines, they are quite different in their beliefs and psychosocial characteristics. Clustering can be done during the visit with the provider. A short validated questionnaire or online profiling tool that patients complete in advance of a consultation could be developed, which automatically calculates which cluster a patient belongs to. The patient's cluster with its unique characteristics can be included in a patient's record and available to providers during the patient visit, similar to reviewing a patient's medical history. This will allow for an effective tailored counselling approach during the short visit time.

Diabetes is a chronic disease condition with reportedly high non-adherence rates. ${ }^{23} 24$ Thus, developing a mechanism that will assist physicians in providing tailored communications to patients who are non-adherent with their diabetes medications can be effective and beneficial.

The objectives of this study were to:

1. Cluster the adherence behaviours of patients with type 2 diabetes based on their beliefs in medicines and illness perceptions.

2. Examine the psychosocial, clinical and sociodemographic characteristics of patient clusters.

This study hypothesised that patient clusters with high concern beliefs and low necessity beliefs will also have high threatening illness perceptions, and groups with low concern beliefs and high necessity beliefs will have low threatening illness perceptions. It is also hypothesised that identified patient clusters will have unique psychosocial, clinical and sociodemographic characteristics.

\section{METHODS}

Using a cross-sectional study design, a face-to-face survey was administered to $\geq 20$-year-old, English-speaking patients with type 2 diabetes who were prescribed at least one oral diabetes medicine daily. Patients were recruited using convenience sampling. Information on eligible patients was retrieved from the electronic health record database of two family medicine clinics in a Midwestern state in the USA.

\section{Data collection}

Front desk receptionist at two clinics provided study information sheets to eligible patients who were waiting for their appointment. After patients reviewed the information, they met with a research assistant to indicate their interests in participating. The research assistant verified the patient's eligibility from the clinic's patient log, administered the informed consent form and completed the 10-20 min survey with the consented participant in a private area at the clinic. Participants were allowed to complete the survey before or after their scheduled clinic appointments, depending on clinic flow and their preferences. Informed consent was obtained from all individual 
participants included in the study. All data collection occurred from March 2016 to August 2016. Participants were compensated with US $\$ 25$ cash, on completion of the survey.

\section{Measures}

Self-reported medication adherence was assessed using the 8-item Morisky Medication Adherence Scale (MMAS8 ), a widely used scale in patients with diabetes. ${ }^{25-29}$ The total score of the MMAS-8 ranged from 0 to 8 , and MMAS-8 scores of $<6,6-<8$ and 8 reflected low, medium and high medication adherence, respectively. ${ }^{25}$ The 10 -item Beliefs in Medicines Questionnaire (BMQ) was used to measure patient beliefs in medications. ${ }^{30}$ The BMQ includes the necessity beliefs and concern beliefs subscales measured on five-point Likert-type scales with 'strongly disagree' to 'strongly agree' response options. The range of scores for each subscale was 5-25, with a higher score meaning stronger concern beliefs or stronger necessity beliefs about the medicine. ${ }^{30}$ The eight-item Brief-Illness Perception Questionnaire (B-IPQ) was used to measure patients' perceptions about diabetes. ${ }^{31}$ This validated instrument includes survey items assessing patient illness perceptions about diabetes along the cognitive domains of the self-regulatory model as well as their emotional responses to having diabetes. Each survey item of the B-IPQ was assessed on a scale of $0-10$ with higher scores indicating stronger threatening perceptions along the illness perception dimensions. ${ }^{31}$

Finally, we assessed other patient psychosocial correlates of medication adherence, that is, health literacy and self-efficacy. Health literacy assessed using the six-item Newest Vital Sign has been extensively used across studies including patients with type 2 diabetes and can be completed in a short time $(3-5 \mathrm{~min}) \cdot{ }^{32-35}$ Each question was scored as ' 0 ' for an incorrect response and ' 1 ' for a correct response for a total score of 0-6. Patients with scores less than 2 represented a high likelihood of inadequate health literacy, 2-3 indicated the possibility of marginal health literacy and more than 3 suggested adequate health literacy. ${ }^{32} 36$

Self-efficacy measured using the 13-item Self-efficacy for Appropriate Medication Use Scale (SEAMS) was used in examining medication self-efficacy in chronic disease management and is appropriate regardless of patient literacy skills. ${ }^{37} 38$ Patients indicated under a range of situations, their level of confidence regarding taking medications correctly using a 3-point Likert scale ( $1=$ not confident, $2=$ =somewhat confident and $3=$ very confident). The total score of the SEAMS ranged from 13 to 39 with higher scores indicating more confidence in adhering to medication use. ${ }^{37}$

Other variables included sociodemographic factors, such as age, gender, highest education level, race, health insurance and the annual household income level; patient clinical factors, such as the number of chronic illnesses, self-reported health status, number of medications used, frequency of daily diabetes medication use, duration of diagnosis of type 2 diabetes and whether the patient used insulin. Besides the main predictor variables, patients' haemoglobin A1c (HbAlc) values in the prior 6 months were retrieved from electronic medical records, with lower HbAlc values $\leq 7.0 \%$ representing better glycaemic control. ${ }^{39}$ The average duration between the day of the latest HbAlc testing and the day of the patient completing the survey was $43.3 \pm 84.6$ days (median: 7 days).

\section{Data analysis}

A two-step cluster analysis was used to classify patients' medication adherence behaviour based on their beliefs in medicines and illness perceptions. ${ }^{40}$ The number of clusters to be formed was kept a priori at four, a number determined by the researchers based on Horne's earlier studies and our prior work. ${ }^{19} 21224142$ The cluster analysis technique organises observed data (eg, patients) into meaningful groups or clusters based on combinations of the independent variables (eg, beliefs in medicines and illness perceptions). This process maximises the similarity of cases within each cluster and also maximises the dissimilarity between the groups based on the log-likelihood distance between the data points. ${ }^{40}$ Using this method allows the clusters to be created without a preconceived notion of what the clusters may look like. Although there are no rules of thumb about the sample size necessary for cluster analysis, prior researchers suggested that the adequate sample size for cluster analysis should be at least $2 \mathrm{~m}$ cases, preferably $5 \times 2 \mathrm{~m}$ cases, where $\mathrm{m}$ is the number of clustering variables. ${ }^{40}{ }^{43}$ Since we used three variables (ie, concern beliefs, necessity beliefs and illness perceptions) for the clustering analysis, a minimal sample size to include no less than eight cases, preferably more than 40 cases, is sufficient to perform a cluster analysis. Additionally, based on an analysis of cluster studies, Dolnicar reports that the median sample size is $293 .{ }^{44}$ In the first step, each data record was either considered as a new cluster or was added to a previously formed cluster. In the second step, the clusters formed from the first step were compared and merged based on the distance between them. Then, we assessed the goodness of fit of the clustering solution. The silhouette measure of cohesion and separation was used to evaluate the overall goodness of fit of the clusters. ${ }^{45}$ A silhouette measure varies between -1 and 1 based on the average distances between the objects. The value of a silhouette measure less than 0.20 indicates a poor solution quality, a value between 0.20 and 0.50 suggests a fair solution, whereas a value of more than 0.50 represents a good solution. ${ }^{46}$ Once categorised, the clusters were then characterised based on various sociodemographic and clinical characteristics. For the continuous variables, one-way analysis of variance was used to determine the psychosocial (eg, health literacy and self-efficacy), clinical (eg, number of medicines) and sociodemographic (eg, age) factors that varied between the clusters. For the categorical variables such as gender and race, $\chi^{2}$ tests were used to examine the differences 
between the clusters. SPSS $(\mathrm{V}, 23.0)$ was used for all the analyses.

\section{Patient and public involvement}

No patients were involved in the development of the study design, the research questions and outcome measures. The results of the study will be disseminated to study participants through access to the published article once published in the journal.

\section{RESULTS}

One hundred and ninety-nine patients were approached and 174 patients participated (87.4\% response rate). The participant's mean age was $58.74(\mathrm{SD}=12.84)$. The majority were women $(57.5 \%)$, non-Hispanic white $(67.8 \%)$ and African-American (24.7\%). Approximately $62.1 \%$ had completed at least a college or technical degree, and $57.5 \%$ had an annual household income of equal or more than $\$ 20000$. Of the 174 patients, $40.8 \%$ had low medication adherence, $35.1 \%$ had medium medication adherence and $24.1 \%$ had high medication adherence.

The two-step cluster analysis produced four distinctive clusters categorised as ambivalent, sceptical, indifferent and accepting. The characteristics of the clusters based on medication adherence, beliefs in medicines, illness perceptions, health literacy, self-efficacy and all demographics are reported in table 1 . The distribution of participants across the clusters ranged from $17.2 \%$ to $30.5 \%$. The silhouette measure was 0.4 , which indicated a satisfactory cluster quality, and the ratio of the largest to smallest cluster was acceptable at 1.77 (figure 1). As hypothesised, high concern beliefs were related to high threatening illness perceptions and low adherence and vice versa. Table 2 describes the distinctive psychosocial and clinical characteristics of each cluster. The ambivalent cluster $(n=30,17.2 \%)$ included low adherent patients with high necessity beliefs, high concern beliefs and high illness perceptions. The sceptical cluster $(n=53$, $30.5 \%$ ) included low adherent patients with low necessity beliefs but high concern beliefs and high illness perceptions. Both the accepting $(\mathrm{n}=40,23.0 \%)$ and indifferent $(\mathrm{n}=51,29.3 \%)$ clusters were composed of patients with high adherence. Significant differences were found between the ambivalent, sceptical, accepting and indifferent adherent clusters based on self-efficacy $(p=0.002)$, beliefs in medicines $(\mathrm{p}<0.001)$, illness perception domains (consequence $(p<0.001)$, personal control $(p<0.001)$, treatment control $(\mathrm{p}<0.001)$, identity $(\mathrm{p}<0.001)$, concern $(p<0.001)$, coherence $(p=0.027)$ and emotional representations $(\mathrm{p}<0.001))$ and HbA1c $(\mathrm{p}<0.05)($ table 1$)$. While non-adherent clusters had low self-efficacy and high HbA1c levels, it was vice versa for the adherent clusters. Patients in the ambivalent non-adherent cluster were younger in age compared with those in the adherent clusters, less likely to have attended some college or technical school and likely to be non-white.

\section{DISCUSSION}

This study used the Extended Self-Regulatory Model to cluster the adherence behaviour of patients with type 2 diabetes based on beliefs in medicines and illness perceptions, as well as examine the characteristics of the clusters, and the significant differences between them. Four clusters with distinct beliefs and psychosocial characteristics associated with each group were formed. The adherence clusters developed in this study by using both beliefs in medicines and illness perceptions are similar to the clusters formed by Horne et al in his previous studies where only beliefs in medicines were used. ${ }^{19} 47$ By including illness perceptions and other psychosocial correlates of adherence, this study identified other pertinent information related to each cluster that may help in developing guided and targeted interventions for providers working with patients with diabetes who may be non-adherent.

Patients in the ambivalent cluster were the least adherent to their medicines followed by the sceptical cluster. These clusters together comprised $48 \%$ of the whole sample. These results are similar to previous studies where these specific clusters represent the non-adherent proportion of a sample. ${ }^{19} 22$ Contrary to a prior study, ambivalent patients had the lowest adherence to diabetes medicines, the strongest concerns about their medicines and the strongest threatening illness perceptions. ${ }^{41}$ In spite of their strong concerns about medicines, ambivalent patients also perceived that their medications were necessary to maintain their health. Further analysis revealed that their strong threatening perceptions about diabetes were from their individual illness perception domains including high emotional representations, lack of treatment control, high concern about illness and less coherence. Despite the belief that medications are necessary, patients in the ambivalent cluster may be cognitively and emotionally overwhelmed by the demands of managing diabetes. Diabetes is psychologically demanding and requires adaptive self-care tasks related to being chronically ill, including taking medications as prescribed. ${ }^{48-50}$ Because of this, when patients fail to self-manage their disease, it may give rise to feelings of guilt, frustration, anger and hopelessness. These negative feelings may foster a pessimistic attitude towards diabetes, leading to negative beliefs about the illness and medication, and poor medication adherence. ${ }^{51}$

Ambivalent patients in this study also had the least self-confidence that they could take and manage their medications correctly and had the lowest health literacy scores. These patients also took the highest number of medicines, had the highest number of chronic illness and had poor glycaemic control (highest HbA1c values). In addition, ambivalent patients were the youngest among the four clusters and had the least education, which might account for their inadequate health literacy and concerns about illnesses and medicines. Tailored adherence interventions aimed at these patients may need to build their self-efficacy and address their low health literacy. Prior 
Table 1 Mean score and percentage comparison of adherence, psychosocial factors and demographics between clusters $(n=174)$

\begin{tabular}{|c|c|c|c|c|c|}
\hline Variables & Total & $\begin{array}{l}\text { Cluster } 1 \\
\text { (Ambivalent) }\end{array}$ & $\begin{array}{l}\text { Cluster } 2 \\
\text { (Sceptical) }\end{array}$ & $\begin{array}{l}\text { Cluster } 3 \\
\text { (Indifferent) }\end{array}$ & $\begin{array}{l}\text { Cluster } 4 \\
\text { (Accepting) }\end{array}$ \\
\hline Number of subjects & 174 & $30(17.2 \%)$ & $53(30.5 \%)$ & $51(29.3 \%)$ & $40(23.0 \%)$ \\
\hline Medication adherence ${ }^{\star \star \star}$ & $5.87 \pm 1.87$ & $4.87 \pm 1.78 \ddagger$ & $5.43 \pm 1.89 \ddagger$ & $6.39 \pm 1.67 \ddagger$ & $6.53 \pm 1.72 \ddagger$ \\
\hline Necessity beliefs (Mean \pm SD) $)^{\star \star \star}$ & $18.88 \pm 4.27$ & $21.93 \pm 2.77 \ddagger$ & $18.23 \pm 1.76 \ddagger$ & $14.59 \pm 3.71 \neq$ & $22.93 \pm 2.18 \ddagger$ \\
\hline Concern beliefs $(\text { Mean } \pm S D)^{\star \star \star}$ & $13.24 \pm 4.35$ & $18.83 \pm 3.66 \ddagger$ & $14.85 \pm 2.07 \ddagger$ & $11.12 \pm 2.71 \ddagger$ & $9.60 \pm 3.41 \ddagger$ \\
\hline $\begin{array}{l}\text { IIIness perceptions (IP) } \\
\left(\text { Mean } \pm \text { SD) } \S^{\star * \star}\right.\end{array}$ & $37.13 \pm 11.06$ & $48.33 \pm 8.39 \ddagger$ & $41.72 \pm 6.23 \ddagger$ & $27.63 \pm 9.87 \ddagger$ & $34.78 \pm 8.07 \ddagger$ \\
\hline Consequence IP§ ${ }^{\star \star \star}$ & $4.88 \pm 2.91$ & $7.30 \pm 2.55 \ddagger$ & $5.13 \pm 2.43 \ddagger$ & $2.94 \pm 2.60 \ddagger$ & $5.20 \pm 2.55 \ddagger$ \\
\hline Timeline IP§ & $8.20 \pm 2.44$ & $8.07 \pm 2.49$ & $8.51 \pm 1.85$ & $7.53 \pm 2.98$ & $8.73 \pm 2.18$ \\
\hline Personal control IP§ & $3.53 \pm 2.51$ & $3.73 \pm 3.06$ & $4.13 \pm 2.31$ & $3.20 \pm 240$ & $3.00 \pm 2.33$ \\
\hline Treatment control IP§ *** & $1.93 \pm 2.03$ & $2.57 \pm 2.54 \ddagger$ & $2.57 \pm 1.82 \ddagger$ & $1.75 \pm 2.01$ & $0.83 \pm 1.34 \ddagger$ \\
\hline 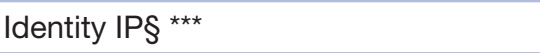 & $4.51 \pm 2.91$ & $7.17 \pm 2.30 \ddagger$ & $5.17 \pm 2.41 \ddagger$ & $2.35 \pm 2.50 \ddagger$ & $4.40 \pm 2.43 \ddagger$ \\
\hline Concern IP§ *** & $6.85 \pm 2.82$ & $8.63 \pm 2.09 \ddagger$ & $7.38 \pm 2.11 \ddagger$ & $4.98 \pm 3.22 \ddagger$ & $7.20 \pm 2.31 \ddagger$ \\
\hline Coherence IP§ * & $2.79 \pm 2.52$ & $3.53 \pm 3.56$ & $3.15 \pm 1.91 \ddagger$ & $2.69 \pm 2.65$ & $1.88 \pm 1.84 \ddagger$ \\
\hline Emotional representation IP§ ${ }^{\star \star \star}$ & $4.45 \pm 3.32$ & $7.33 \pm 2.71 \ddagger$ & $5.68 \pm 2.56 \ddagger$ & $2.20 \pm 2.99 \ddagger$ & $3.55 \pm 2.72 \ddagger$ \\
\hline Self-efficacy (Mean \pm SD) $\|^{* *}$ & $33.24 \pm 5.96$ & $31.30 \pm 6.65 \ddagger$ & $32.02 \pm 6.18 \ddagger$ & $33.47 \pm 6.11$ & $36.00 \pm 3.64 \ddagger$ \\
\hline Health literacy $($ Mean \pm SD)†† & $3.72 \pm 2.02$ & $3.13 \pm 1.94$ & $3.96 \pm 1.91$ & $3.80 \pm 2.11$ & $3.75 \pm 2.08$ \\
\hline Inadequate & & 7 (23.3\%) & $7(13.2 \%)$ & $7(17.5 \%)$ & $10(19.6 \%)$ \\
\hline Marginal & & $11(36.7 \%)$ & $10(18.9 \%)$ & $9(22.5 \%)$ & $9(17.6 \%)$ \\
\hline Adequate & & $12(40.0 \%)$ & $36(67.9 \%)$ & $24(60 \%)$ & $32(62.7 \%)$ \\
\hline Age & $58.74 \pm 12.84$ & $55.17 \pm 14.00$ & $57.85 \pm 11.48$ & $59.04 \pm 13.92$ & $62.20 \pm 11.73$ \\
\hline White ${ }^{\star *}$ & $118(67.8 \%)$ & $12(40.0 \%)$ & $38(71.7 \%)$ & $29(72.5 \%)$ & $39(76.5 \%)$ \\
\hline Female & $100(57.5 \%)$ & $18(60.0 \%)$ & $30(56.6 \%)$ & $20(50.0 \%)$ & $32(62.7 \%)$ \\
\hline Education higher than high school & $108(62.1 \%)$ & $15(50.0 \%)$ & $32(60.4 \%)$ & $35(68.6 \%)$ & $26(65.0 \%)$ \\
\hline \multicolumn{6}{|l|}{ Education } \\
\hline Completed $8^{\text {th }}$ grade or less & $4(2.3 \%)$ & $1(3.3 \%)$ & $0(0.0 \%)$ & $1(2.0 \%)$ & $2(5.0 \%)$ \\
\hline Some high school & $15(8.6 \%)$ & $5(16.7 \%)$ & $3(5.7 \%)$ & $5(9.8 \%)$ & $2(5.0 \%)$ \\
\hline High school graduate or GED & $47(27.0 \%)$ & $9(30.0 \%)$ & $18(34.0 \%)$ & $10(19.6 \%)$ & $10(25.0 \%)$ \\
\hline Some college or technical school & $67(38.5 \%)$ & $10(33.3 \%)$ & $14(26.4 \%)$ & $26(51.0 \%)$ & $17(42.5 \%)$ \\
\hline College graduate & $24(13.8 \%)$ & $3(10.0 \%)$ & $12(22.6 \%)$ & $6(11.8 \%)$ & $3(7.5 \%)$ \\
\hline Graduate degree & $17(9.8 \%)$ & $2(6.7 \%)$ & $6(11.3 \%)$ & $3(5.9 \%)$ & $6(15.0 \%)$ \\
\hline Number of medications $(\text { Mean } \pm S D)^{\star \star \star}$ & $7.77 \pm 3.89$ & $9.07 \pm 4.21 \ddagger$ & $8.19 \pm 4.03 \ddagger$ & $5.80 \pm 2.86 \ddagger$ & $8.75 \pm 3.75 \ddagger$ \\
\hline Number of illness $(\text { Mean } \pm S D)^{\star *}$ & $3.86 \pm 1.82$ & $4.50 \pm 2.03 \ddagger$ & $3.89 \pm 1.96$ & $3.22 \pm 1.47 \ddagger$ & $4.28 \pm 1.66 \ddagger$ \\
\hline $\begin{array}{l}\text { Duration of diabetes diagnosed } \\
(\text { Mean } \pm \text { SD })^{\star}\end{array}$ & $9.58 \pm 7.08$ & $8.75 \pm 5.79$ & $9.25 \pm 6.30$ & $8.03 \pm 7.14 \ddagger$ & $12.61 \pm 8.13 \ddagger$ \\
\hline HbA1c level* & $7.66 \pm 1.64$ & $8.31 \pm 2.14 \ddagger$ & $7.86 \pm 1.58$ & $7.17 \pm 1.32 \ddagger$ & $7.52 \pm 1.51$ \\
\hline Health status $\neq \ddagger$ ** & $2.64 \pm 0.80$ & $2.13 \pm 0.90 \ddagger$ & $2.72 \pm 0.77 \ddagger$ & $2.86 \pm 0.75 \ddagger$ & $2.65 \pm 0.70$ \\
\hline
\end{tabular}

${ }^{*} p<0.05,{ }^{* *} p<0.01,{ }^{* * *} p<0.001$.

†Self-reported medication adherence was measured with the 8-item Morisky Medication Adherence Scale.

$\ddagger$ Significant differences based on the post-hoc analysis.

$\S$ Higher scores indicate higher specific illness perceptions. Personal control, treatment control, and coherence are reverse scored.

१The score of the self-efficacy on medication use ranges from 13 to 39.13 items on a 3 point scale. Higher scores indicate higher levels of self-efficacy.

††Heath literacy was measured with the Newest Vital Sign (NVS).

$\ddagger \ddagger$ One item on a 5 point scale. Higher scores indicate better self-reported health status.

GED, general equivalency development (or general equivalency diploma); HbA1c, haemoglobin A1c; IP, illness perception. 


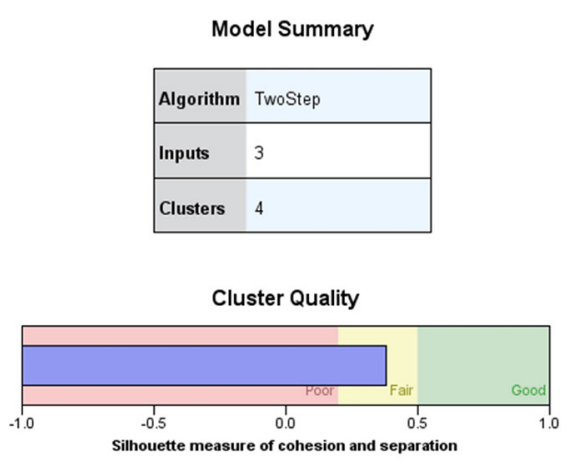

Figure 1 Test statistics of clustering analysis.

research shows that by providing information in simple plain language, using teach-back techniques and showing patients how they can be expert self-managers and engage in self-monitoring, patients are more likely to feel more in control of their illness, less concerned about the illness and manage their illness more effectively. ${ }^{52}$

In the sceptical cluster, patients had strong concerns about medicines and threatening illness perceptions, although not at a pronounced degree as the ambivalent group. They also did not think their medications were necessary. Contrary to previous studies in asthma, epilepsy, inflammatory bowel disease, depression and cardiac disease, where the sceptical groups were most non-adherent to their medications, the sceptical group
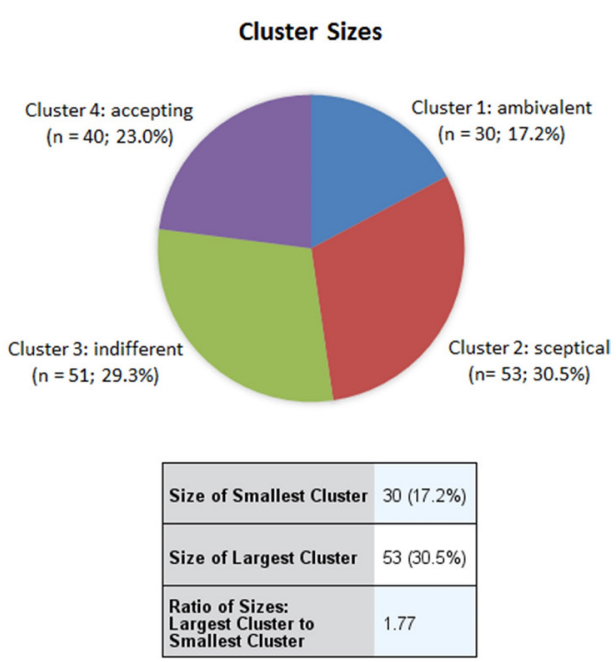

of patients with diabetes in this study did not have the lowest medication adherence. ${ }^{212241}$ Although this cluster of patients had perceptions of strong consequences from the illness, lack of treatment control, high concerns and emotional representations, were experiencing many symptoms due to diabetes and were not confident they could manage their medications, they also had high health literacy and good understanding of their diabetes. For these patients, it is possible that because they have an increased ability to search, understand and process health information, they are engaged in seeking information to manage their diabetes themselves, perform other diabetes self-management practices and therefore do not believe they need medicines. A prior study has shown that

Table 2 Beliefs, psychosocial and clinical characteristics of the clusters

\begin{tabular}{|c|c|c|c|c|}
\hline & \multicolumn{2}{|c|}{ Clusters with non-adherence behaviour } & \multicolumn{2}{|c|}{ Clusters with adherence behaviour } \\
\hline & $\begin{array}{l}\text { Cluster } 1 \\
\text { (ambivalent) }\end{array}$ & $\begin{array}{l}\text { Cluster } 2 \\
\text { (sceptical) }\end{array}$ & $\begin{array}{l}\text { Cluster } 3 \\
\text { (indifferent) }\end{array}$ & $\begin{array}{l}\text { Cluster } 4 \\
\text { (accepting) }\end{array}$ \\
\hline \multirow[t]{2}{*}{ Beliefs in medicines } & High NB & Low NB & Low NB & High NB \\
\hline & High CB & High CB & Low CB & Low CB \\
\hline SE & Low SE & Low SE & High SE & High SE \\
\hline $\mathrm{HL}$ & Low HL & High HL & High HL & High HL \\
\hline Glycaemic control & High $\mathrm{HbA1c}$ & High $\mathrm{HbA} 1 \mathrm{c}$ & Low HbA1c & Low HbA1c \\
\hline \multirow{3}{*}{$\begin{array}{l}\text { Illness perception } \\
\text { domains }\end{array}$} & High consequence & High consequence & Low consequence & High consequence \\
\hline & High coherence & High coherence & Low coherence & Low coherence \\
\hline & $\begin{array}{l}\text { High emotional } \\
\text { representation }\end{array}$ & $\begin{array}{l}\text { High emotional } \\
\text { representation }\end{array}$ & $\begin{array}{l}\text { Low emotional } \\
\text { representation }\end{array}$ & $\begin{array}{l}\text { Low emotional } \\
\text { representation }\end{array}$ \\
\hline
\end{tabular}

The high and low values for each variable is compared based on the mean values from all participants.

$\mathrm{CB}$, concern beliefs; HbA1c: haemoglobin A1c levels; HL, health literacy; IP, illness perceptions; NB, necessity beliefs; SE, self-efficacy. 
patients with no educational qualifications (possibly tied to health literacy) are likely to have doubts about their personal need for medicines compared with patients with any formal educational qualifications. ${ }^{21}$ Additionally, their self-perceived better health status may also be contributing to their perception that medications are not necessary for maintaining their health, hence, making them sceptical. In spite of their high health literacy, sceptical patients' low self-efficacy may lead to their poor glycaemic control especially as prior studies report the strong influence of self-efficacy on diabetes control. ${ }^{53} 54$ Adherence interventions that target concerns about medicines and illness and also aim to motivate patients towards medication use might need to be developed for these group of patients.

Patients in the indifferent and accepting clusters were adherent to their medicines, though different in their beliefs in medicines. Similar to prior studies, patients in the accepting group were more likely to be adherent to their medicines. ${ }^{19212241}$ These patients are generally not concerned about their illness, believe that their medications are necessary and are least concerned about them, feel the most confident that they can take their medications correctly and have the ability to process and understand health information. This group of patients, however, still believe that their diabetes affects their life and still have some concern about it. The accepting patients were the oldest in age, the most educated and have had their diabetes longer compared with patients in other clusters. Since these patients' HbAlc values still show that their diabetes is uncontrolled and using medications as part of diabetes management may not be concerning, interventions may seek to address concerns about their diabetes, especially as it relates to other complex diabetes self-management issues, such as checking blood sugars, exercising, diet and so on. Since these older and well-educated patients have had diabetes for a long time and used many medications, providers may continue to encourage self-monitoring of symptoms, adverse drug events and check for other indicators of poor diabetes outcomes, such as high blood pressure and high cholesterol. ${ }^{55}$

Contrary to previous studies where patients who were in the indifferent cluster were reported to be non-adherent to their medicines, the current study showed that the patients in this cluster were adherent to their medicines and their diabetes seemed to be in better control than patients in the three other clusters. ${ }^{19} 22$ Although the patients in the indifferent cluster were the least likely to believe that their medications were necessary, they were also least concerned about their medicines, were not threatened by their illness and were not emotionally affected by it (low emotional representation). Also, they experienced few symptoms and had the least concern about their illness. It is also possible that because these patients were taking the lowest number of medicines and had the lowest number of chronic illness, they were healthier compared with other patients and therefore more likely to easily manage their medicines. Providers may continue to address the needs for taking medicines and provide interventions that emphasise the need for taking medicines.

This study has several strengths. Horne et al classified patients' adherence behaviours based on beliefs in medicines using the midpoint score of the BMQ ${ }^{19}$ However, this current study used the clustering technique to allow for algorithm-based grouping based on both beliefs in medicines and illness perceptions founded on the Extended Self-Regulatory Model. Prior research has highlighted the importance of content and theory-driven components to enable replication of successful adherence interventions. ${ }^{52}$ While it is important to address diabetes non-adherence via clinical interventions, we cannot underestimate the impact of patient psychosocial factors such as their individual perceptions of medication and illness, self-efficacy and health literacy in the management of diabetes. Brief, valid and reliable questionnaires that can easily quantify these psychosocial factors are available and may be included in adherence support programmes. ${ }^{21}$

The study limitations are the use of a convenience sample from two clinics in one state, hereby limiting the generalisability of the study. The use of a self-reported measure to evaluate medication adherence, rather than objective measures such as the use of pill counts, might lead to overestimation. However, prior studies show the reliability and validity of self-report adherence measures. ${ }^{25} 27$ Data were collected either before or after patients' medical encounter depending on the flow of the clinic. The timing of the medical encounter may influence patient responses to questions about illness and treatment beliefs. This variable was not accounted for in the data analysis. The concurrent assessment of illness perceptions, beliefs in medicines and adherence in a cross-sectional manner is a limitation. A longitudinal study that evaluates changes in beliefs over time and examines how these changes relate to changes in behaviour and outcomes will be considered in the future. HbAlc was measured retrospectively. Although we used the most recent values from patients' medical record that is acceptable by clinical practitioners for standard diabetes care, this retrospective measurement of HbA1c could have limited our results. Although the B-IPQ total score categorises respondents into two categories without taking into consideration the individual domains of the illness perceptions, this was needed for clustering their adherence. Once the clusters were formed, the illness perception domain characteristics of each cluster were analysed and compared.

\section{CONCLUSIONS}

This study used a cluster analysis to characterise patients' adherence behaviour based on their beliefs in both medicines and illnesses and psychosocial factors. Using evidence-based theoretical approaches, four clusters were formed with characteristics that suggest different types 
of interventions for each cluster. Medication non-adherence is a complex behaviour to understand, and targeted interventions are often recommended. Data that can help discriminate between large groups of non-adherent individuals are needed in developing more personalised interventions. Although a large number of patients in two separate clusters (ambivalent and sceptical) were non-adherent to their medicines, patients within each non-adherent cluster still had distinct beliefs in medicines, illness perceptions and other psychosocial characteristics that may help providers target tailored behavioural, psychological-based adherence interventions (for ambivalent clusters), as well as education and motivation-based adherence interventions (for sceptical clusters). Also, patients who are adherent may still need interventions that support and/or enhance their use of medicines (for indifferent clusters) and support individualised self-management strategies used for control of illness (for accepting clusters).

Acknowledgements The authors would like to thank Dr Paul Smith for helping with part of the study's data collection process. Use of the MMAS is protected by US copyright laws. Permission for use is required. A licence agreement is available from: Donald E Morisky, MMAS Research LLC 14725 NE 20th St. Bellevue, WA 98007, or from dmorisky@gmail.com. We have obtained written permission from copyright owners for any excerpts from copyrighted works that are included and have credited the sources in the article or the supplemental materials. Portions of this work were presented at the 2017 American Pharmacist Association Meeting and published in an abstract by the Journal of the American Pharmacists Association (Volume 57, Issue 3, May-June 2017, pages e1-e142).

Contributors $00 \mathrm{~S}$ and EU designed the study. 00S, Y-MH and CL were involved in data collection and data analysis. OOS wrote the manuscript, and EU and Y-MH critically revised the content. All authors approved the final version of the manuscript.

Funding The authors have not declared a specific grant for this research from any funding agency in the public, commercial or not-for-profit sectors.

Competing interests None declared.

Patient consent Obtained.

Ethics approval The Health Sciences Institutional Review Board of the University of Wisconsin-Madison approved the study.

Provenance and peer review Not commissioned; externally peer reviewed.

Data sharing statement № additional data are available.

Open access This is an open access article distributed in accordance with the Creative Commons Attribution Non Commercial (CC BY-NC 4.0) license, which permits others to distribute, remix, adapt, build upon this work non-commercially, and license their derivative works on different terms, provided the original work is properly cited, appropriate credit is given, any changes made indicated, and the use is non-commercial. See: http://creativecommons.org/licenses/by-nc/4.0/.

\section{REFERENCES}

1. Hu D, Juarez DT, Yeboah M, et al. Interventions to increase medication adherence in African-American and Latino populations: a literature review. Hawaii J Med Public Health 2014;73:11-18.

2. Haynes RB, Taylor DW, Sackett DL. Compliance in health care, 1979.

3. Leventhal H, Nerenz DR, Purse J. Illness representations and coping with health threats, 1984.

4. Kelly JA, Kalichman SC. Behavioral research in HIV/AIDS primary and secondary prevention: recent advances and future directions. $J$ Consult Clin Psychol 2002;70:626-39.

5. Agency for Healthcare Research and Quality. Better adherence to diabetes medications means fewer hospitalizations and emergency department visits. 2011 https://archive.ahrq.gov/news/newsletters/ research-activities/mar11/0311RA8.html (Accessed 13 Mar 2018).
6. Haynes RB, Ackloo E, Sahota N, et al. Interventions for enhancing medication adherence. Cochrane Database Syst Rev 2008:CD000011.

7. Balkrishnan R, Rajagopalan R, Camacho FT, et al. Predictors of medication adherence and associated health care costs in an older population with type 2 diabetes mellitus: a longitudinal cohort study. Clin Ther 2003;25:2958-71.

8. Gonzalez JS, Tanenbaum ML, Commissariat PV. Psychosocial factors in medication adherence and diabetes self-management: Implications for research and practice. Am Psychol 2016;71:539-51.

9. Horne R, Weinman J. Self-regulation and self-management in asthma: exploring the role of illness perceptions and treatment beliefs in explaining non-adherence to preventer medication. Psychol Health 2002;17:17-32.

10. Horne R. Representations of medication and treatment: advances in theory and measurement. London: Harwood Academic, 1997.

11. Horne R. Treatment perceptions and self-regulation. The selfregulation of health and illness behaviour. 1 edn: Routledge, 2003:138-53.

12. Broadbent E, Donkin L, Stroh JC. Illness and treatment perceptions are associated with adherence to medications, diet, and exercise in diabetic patients. Diabetes Care 2011;34:338-40.

13. Shiyanbola OO, Nelson J. Illness perceptions, beliefs in medicine and medication non-adherence among South Dakota minority women with diabetes: a pilot study. S D Med 2011;64:365-8.

14. Gunther M, Foisy M, Houston S, et al. Treatment beliefs, illness perceptions, and non-adherence to antiretroviral therapy in an ethnically diverse patient population. Int J Clin Pharm 2014;36:105-11.

15. Unni EJ, Shiyanbola O, Farris KB. Medication adherence: a complex behavior of medication and illness beliefs. Aging health 2013;9:377-87.

16. Leventhal $\mathrm{H}$, Brissette I, Leventhal EA. The common-sense model of self-regulation of health and illness. The self-regulation of health and illness behaviour 2003;1:42-65.

17. Phillips LA, Leventhal EA, Leventhal $H$. Factors associated with the accuracy of physicians' predictions of patient adherence. Patient Educ Couns 2011;85:461-7.

18. Phillips LA, Leventhal $\mathrm{H}$, Leventhal EA. Physicians' communication of the common-sense self-regulation model results in greater reported adherence than physicians' use of interpersonal skills. Br J Health Psychol 2012;17:244-57.

19. Horne R, Parham R, Driscoll R, et al. Patients' attitudes to medicines and adherence to maintenance treatment in inflammatory bowel disease. Inflamm Bowel Dis 2009;15:837-44.

20. Smithson WH, Hukins D, Colwell B, et al. Developing a method to identify medicines non-adherence in a community sample of adults with epilepsy. Epilepsy Behav 2012;24:49-53.

21. Chapman SC, Horne R, Chater A, et al. Patients' perspectives on antiepileptic medication: relationships between beliefs about medicines and adherence among patients with epilepsy in UK primary care. Epilepsy Behav 2014;31:312-20.

22. Unni E, Shiyanbola OO. Clustering medication adherence behavior based on beliefs in medicines and illness perceptions in patients taking asthma maintenance medications. Curr Med Res Opin 2016;32:113-21.

23. Feldman BS, Cohen-Stavi CJ, Leibowitz M, et al. Defining the role of medication adherence in poor glycemic control among a general adult population with diabetes. PLoS One 2014;9:e108145.

24. luga AO, McGuire MJ. Adherence and health care costs. Risk Manag Healthc Policy 2014;7:35-44.

25. Morisky DE, Ang A, Krousel-Wood M, et al. Predictive validity of a medication adherence measure in an outpatient setting. $J$ Clin Hypertens 2008;10:348-54.

26. Sakthong P, Chabunthom R, Charoenvisuthiwongs R. Psychometric properties of the Thai version of the 8-item Morisky Medication Adherence Scale in patients with type 2 diabetes. Ann Pharmacother 2009;43:950-7.

27. Krousel-Wood M, Islam T, Webber LS, et al. New medication adherence scale versus pharmacy fill rates in seniors with hypertension. Am J Manag Care 2009;15:59-66.

28. Al-Qazaz HKh, Hassali MA, Shafie AA, et al. The eight-item Morisky Medication Adherence Scale MMAS: translation and validation of the Malaysian version. Diabetes Res Clin Pract 2010;90:216-21.

29. Morisky DE, DiMatteo MR. Improving the measurement of selfreported medication nonadherence: response to authors. J Clin Epidemiol 2011;64:255-7. discussion 258-263.

30. Horne R, Weinman J, Hankins M. The beliefs about medicines questionnaire: the development and evaluation of a new method for assessing the cognitive representation of medication. Psychol Health 1999:14:1-24. 
31. Broadbent E, Petrie KJ, Main J, et al. The brief illness perception questionnaire. J Psychosom Res 2006;60:631-7.

32. Weiss BD, Mays MZ, Martz W, et al. Quick assessment of literacy in primary care: the newest vital sign. Ann Fam Med 2005;3:514-22.

33. Shigaki C, Kruse RL, Mehr D, et al. Motivation and diabetes selfmanagement. Chronic IIIn 2010;6:202-14.

34. Kirk JK, Grzywacz JG, Arcury TA, et al. Performance of health literacy tests among older adults with diabetes. J Gen Intern Med 2012;27:534-40.

35. Haun JN, Valerio MA, McCormack LA, et al. Health literacy measurement: an inventory and descriptive summary of 51 instruments. J Health Commun 2014;19(Suppl 2):302-33.

36. Huang YM, Shiyanbola OO, Smith PD, et al. Quick screen of patients' numeracy and document literacy skills: the factor structure of the Newest Vital Sign. Patient Prefer Adherence 2018;12:853-9.

37. Risser J, Jacobson TA, Kripalani S. Development and psychometric evaluation of the Self-efficacy for Appropriate Medication Use Scale (SEAMS) in low-literacy patients with chronic disease. J Nurs Meas 2007;15:203-19.

38. Lavsa SM, Holzworth A, Ansani NT. Selection of a validated scale for measuring medication adherence. J Am Pharm Assoc 2011;51:90-4.

39. American Diabetes Association. Standards of Medical Care in Diabetes-2017 abridged for primary care providers. Clin Diabetes 2017;35:5-26.

40. Sarstedt M, Mooi E. Cluster analysis. A concise guide to market research: Springer, 2014:273-324.

41. Tibaldi G, Clatworthy J, Torchio E, et al. The utility of the Necessity-Concerns Framework in explaining treatment non-adherence in four chronic illness groups in Italy. Chronic IIIn 2009;5:129-33.

42. Chapman SC, Horne R, Eade R, et al. Applying a perceptions and practicalities approach to understanding nonadherence to antiepileptic drugs. Epilepsia 2015;56:1398-407.

43. Formann AK. Die latent-class-analyse: Einführung in Theorie und Anwendung: Beltz, 1984.
44. Dolnicar S. A review of unquestioned standards in using cluster analysis for data-driven market segmentation, 2002.

45. Rousseeuw PJ. Silhouettes: a graphical aid to the interpretation and validation of cluster analysis. J Comput Appl Math 1987;20:53-65.

46. Mooi E, Sarstedt M. Cluster analysis. A concise guide to market research: Springer, 2010:237-84.

47. Horne R, Chapman SC, Parham R, et al. Understanding patients adherence-related beliefs about medicines prescribed for longterm conditions: a meta-analytic review of the Necessity-Concerns Framework. PLoS One 2013;8:e80633.

48. Snoek FJ, Pouwer F, Welch GW, et al. Diabetes-related emotional distress in Dutch and U.S. diabetic patients: cross-cultural validity of the problem areas in diabetes scale. Diabetes Care 2000;23:1305-9.

49. Rubin RR. Adherence to pharmacologic therapy in patients with type 2 diabetes mellitus. Am J Med 2005;118(Suppl 5A):27S-34.

50. Samson A, Siam H. Adapting to major chronic illness: a proposal for a comprehensive task-model approach. Patient Educ Couns 2008;70:426-9.

51. Van der Ven N, Weinger K, Snoek F. Cognitive behaviour therapy: how to improve diabetes self-management. Diabetes voice 2002; 47:10-13

52. Clarkesmith DE, Pattison HM, Borg Xuereb C, et al. Developing a Complex Educational-Behavioural Intervention: The TREAT Intervention for Patients with Atrial Fibrillation. Healthcare 2016;4:10.

53. McCleary-Jones V. Health literacy and its association with diabetes knowledge, self-efficacy and disease self-management among African Americans with diabetes mellitus. Abnf J 2011;22:25-32.

54. Sleath B, Carpenter DM, Blalock SJ, et al. Development of a new diabetes medication self-efficacy scale and its association with both reported problems in using diabetes medications and self-reported adherence. Patient Prefer Adherence 2016;10:1003-10.

55. Benoit SR, Fleming R, Philis-Tsimikas A, et al. Predictors of glycemic control among patients with Type 2 diabetes: a longitudinal study. BMC Public Health 2005;5:36. 